\title{
Between traditional and mobile language learning
}

\author{
Neva ČEBRON ${ }^{1}$, Lara SORGO², Emma Beatriz VILLEGAS CUNJA ${ }^{3}$
}

\begin{abstract}
The paper focuses first on the novelties accessible to foreign language learning adults by MALL and mobile language learning, thus drawing a brief overview of the research into novel affordances they offer and implications for a new language learning methodology. Secondly, we explore attitudes of adult learners (tertiary students, academic and administrative staff) to studying or improving language skills in various languages immersed in the ICT, in particular the options proposed by the language learning mobile apps. In order to gather adult learners' views, a quantitative research, based on an e-questionnaire, was carried out among 1028 participants from 6 EU countries within the international LanGuide project. The results of this research lead to re-evaluation of some teaching approaches and suggest recommendations for teaching practitioners and materials developers.
\end{abstract}

Keywords: eLearning, teaching approaches, LanGuide project, multilingualism.

\section{Introduction}

The pervasive presence of ICT (information and communication technology) in everyday life and the appeal these technologies have for our students, force teachers of foreign languages to consider how language teaching might be adapted to include the new tools into their teaching practice. The surge in the development of ICT supported language-learning devices, especially language learning apps, and a wealth of research focusing on exploration of the new affordances of elearning indicate new options for acquisition of foreign languages as a life-long learning practice which the LanGuide project seeks to exploit and advance.

The paper reports on a survey carried out among respondents (students, academic and administrative staff) at 6 institutions of higher education in Slovenia, Romania, Croatia, Spain and Sweden. The purpose of the research was to examine the views, practices and attitudes of respondents with regard to using ICT for

\footnotetext{
1 University of Primorska, Slovenia, neva.cebron@fhs.upr.si

2 University of Primorska, Slovenia, lara.sorgo@gmail.com

3 University of Primorska, Slovenia, beatriz.cunja@fhs.upr.si
} 
foreign language acquisition, thus helping the international partnership to establish clear goals for developing learning materials in the languages of the partnership.

Drawing on the insights provided by earlier studies this paper aims to answer the following questions: 1) How familiar are our respondents with ICT and mobile apps as self-learning tools for language acquisition? 2) What are their expected needs and motivations? 3) What methodological adaptations should be considered in eLearning syllabi and materials?

The research was carried out as part of the activities within the LanGuide project (KA2-HE/19), co-funded by the European Commission.

\section{Views on traditional and mobile language learning}

A number of researchers point out to a disconnect between the world of education and the mobile technology that learners interact with mostly beyond the classrooms and lecture halls (e.g. Walsh 2010; Kukulska-Hulme et al. 2015; Jie et al. 2020), while also identifying a lack of new pedagogical frameworks that could guide educational endeavours for integration of mobile learning (henceforth mLearning) into the curricula (e. g. Sharples 2006; Bernacki et al. 2020). From recent research into mobile pedagogy, it has also become clear that education in the mobile age cannot replace formal education; rather it can offer a way to extend, support and scaffold learning outside the classroom (Mutiaraningrum and Nugroh 2021).

Research evidences an important paradigm shift between the two educational systems. Namely, the primary goal of the traditional educational system was effective transmission of cannons of scholarship in a formal educational setting, while the construction of knowledge in a mobile era occurs as information processing in the interaction through and with personal and mobile technology in a range of environments (Sharples 2006).

In terms of language acquisition, the traditional, well-paced acquisition process requires persistence and stamina, since a "drip-feed approach [...] often leads to frustration as learners feel they have been studying for years without making much progress" (Lightbown and Spada 2006, 186). On the other hand, mobile assisted language learning (henceforth MALL) and mLearning ${ }^{4}$ gives students the opportunity to engage with language during lessons and between

\footnotetext{
${ }^{4}$ mLearning refers to affordances of language tuition supplemented by informal learning on smartphones, whereas MALL - a subfield of mLearning - covers a broad range of activities for individual practice of language skills and knowledge, including language courses and lessons, but also exploratory learning in urban settings, collaborative and competitive language tasks, reference books and similar.
} 
lessons with personalised, self-paced and learner-centred activities (Viberg and Grönlund 2012), thus allowing a more agile, focused and needs-centred development of communicative skills in a foreign language.

Such a shift of objectives and goals calls for a thorough rethinking of teaching and learning approaches, as well as the development of effective methods and teaching materials for MALL and mLearning. Technology itself plays a role in reshaping people's preferences, perceptions, and attitudes, leading to the idea of a methodology co-constructed in a sociotechnical system (Viberg and Grönlund 2012) and drawing on lessons learned from practices developed within distance learning and computer assisted language learning (henceforth CALL), while adjusting to the new demands such as flexibility, portability and spontaneity (Mutiaraningrum and Nugroh 2021).

Narrowing the view to the main objective of the LanGuide project, namely, to the design of a mobile app for language acquisition, it needs to be observed that "there are apps for all aspects of language learning, but very little consideration has been given to the pedagogical premises that underpin the design of mobile apps" (Brick and Cervi-Wilson 2015, 24). These apps provide a multifaceted capability that offers time and space flexibility and adaptability that facilitate the changeable environment favoured by a variety of self-learners from students to professionals (Ibacache 2019), but the convenience of virtual learning and "the ubiquity of mLearning options affect the manner in which one learns as language learning intertwines with users' daily life activity and work" (Kukulska-Hulme 2012, 10). Enhancing motivation of self-regulated learners still seems to require a wellorganized design, relevant content and clear scope (Broadbent 2017), as well as a learner and knowledge centred approach. Successful mLearning of a foreign language should build on the skills and knowledge of students, enabling them to reason from their own experience, while providing a structured syllabus of validated knowledge, taught efficiently and with inventive use of concepts and methods (Sharples, Taylor and Vavoula 2005; Elbabour and Head 2020).

Consequently, the new medium entails also a shift in roles and responsibilities of teachers, thus Conole and Alevizou (2010) highlight that "the boundaries between traditional roles (teacher and learner) and functions (teaching and learning) are blurring. 'Teachers' need to be learners in order to make sense of and take account of new technologies in their practices" (p. 44). Teachers and materials writers need to be aware of the specific ways in which digital devices can conveniently be used inside and outside the classroom by their end-users, as well as of the specific sites and apps they frequently access and the ways they plan to use their digital devices (Brick and Cervi-Wilson 2015). 
We can conclude that mobile language learning has changed the approach to language acquisition, while a number of issues still need to be addressed and analysed in order to provide a meaningful, productive user experience on language-learning apps.

\section{Research design}

\subsection{E-questionnaire}

In order to gather data an e-questionnaire of 21 questions was developed and opened on-line for 3 weeks between April and May 2021. It received 1028 responses from 6 institutions of higher education (University of Primorska - UP, University of Rijeka - UNIRI; University of Zadar - UNZD; University of CastillaLa Mancha - UCLM; Mälardalen University - MDH; Transilvania University of Brasov - UTBV). However, the number of responses to some questions was lower for various reasons. The data collected was mainly quantitative in nature, seeking to capture respondents' use and attitudes to mLearning.

The first part of the questionnaire recorded core respondents' data, such as age, gender, institutional affiliation, status (student, administrative staff or teacher), and previous experience with learning English. The participants were also asked to assess their level of ICT skills (basic, intermediate, advanced) and the type of electronic device they use (PC, tablet, mobile phone), the ease of accessing the Internet, as well as how, when and where they mostly use their devices.

The main goal of the questionnaire was, however, to gain an understanding whether the participants had used mobile apps for foreign language acquisition and the type and frequency of linguistic information they had looked for on the Internet.

In the last part of the survey, respondents had to agree or disagree with a series of statements (five-point Likert scale) regarding their use of new technologies in language acquisition and assess the likelihood of their engaging in language learning via mobile apps sometime in the future.

The following sections analyse some relevant issues gleaned from the survey.

\subsection{Participants}

Our respondents classified as students, administrative staff and teachers from the LanGuide project partner institutions. A total of 1028 respondents completed the whole questionnaire: 174 at UP (16.92\%) 154 at UNIRI (14.98\%), 230 at UNZD 
(22.37\%), 150 at UCLM (14.59\%), 41 at MDH (3.98\%) and 279 at UTBV (27.14\%) (Table 1).

Table 1. Respondents by institutions and categories

\begin{tabular}{|l|r|r|r|r|}
\hline \multirow{2}{*}{ Institution } & \multicolumn{2}{|l|}{ What do you participate as? } \\
\cline { 2 - 5 } & Student & \multicolumn{2}{|c|}{ Administrative staff } & \multicolumn{2}{c|}{ Teacher } & \multicolumn{2}{c|}{ Total } \\
\cline { 2 - 5 } & $\mathrm{n}$ & $\mathrm{n}$ & $\mathrm{n}$ & $\mathrm{n}$ \\
\hline UP & 105 & 34 & 35 & $\mathbf{1 7 4}$ \\
\hline UNIRI & 101 & 11 & 42 & $\mathbf{1 5 4}$ \\
\hline UNZD & 155 & 30 & 45 & $\mathbf{2 3 0}$ \\
\hline UCLM & 95 & 14 & 41 & $\mathbf{1 5 0}$ \\
\hline MDH & 22 & 5 & 14 & $\mathbf{4 1}$ \\
\hline UTBV & 207 & 15 & 57 & $\mathbf{2 7 9}$ \\
\hline Total & $\mathbf{6 8 5}$ & $\mathbf{1 0 9}$ & $\mathbf{2 3 4}$ & $\mathbf{1 0 2 8}$ \\
\hline
\end{tabular}

Of the respondents, $67.5 \%$ identified as female, $30.7 \%$ as male and $1.8 \%$ preferred not to answer this question. The majority reported being students $(66.6 \%)$, followed by university teachers $(22.8 \%)$ and administrative staff $(10.6 \%)$. The average age of student respondents was 23.3 years, teachers 44.8 years and administrative staff 41.9 years.

Most respondents (69.2\%) had studied English in formal courses for more than 10 years, while the $21.1 \%$ of students averaged $6-9$ years of learning English. Only $8.6 \%$ of respondents had studied English just $1-5$ years, while $1.1 \%$ never studied it before.

With regard to their level of digital competence, $58.4 \%$ considered themselves to have a good level of digital skills, evaluating them at an intermediate level. $32.5 \%$ respondents placed themselves at an advanced level and $9.1 \%$ at a basic level.

Due to space limitations, this paper compares only the answers gathered from the different types of respondents and not in terms of other variables, while examining only the salient findings of this research.

\section{Results and discussion}

Overall, the e-questionnaire results indicate great ease in connecting to the Internet at all the environments surveyed, as confirmed by $91.4 \%$ of respondents, who also reported frequent use of smartphones or other devices either for texting 
or chatting $(88 \%)$, social networking $(75.1 \%)$, or to search for information $(57.1 \%)$ and advice for language use (30.6\%).

The latter point was further explored in a question regarding the frequency of use of electronic devices to study or improve their English language skills. The answers suggest that the PC/laptop and smartphone are the preferred tools with all groups. However, it is mainly students who use their PCs (35.2\%) or smartphones (39.7\%) daily to enhance their English. The administrative staff, who prefer to use their PC, mostly engage in language learning activities only a few times a month $(33 \%)$, while roughly a quarter $(26.6 \%)$ of the respondents from this group devise some time to English daily. Similarly, the teacher respondents prefer the PC $(33.8 \%)$ to the smartphone (24.4\%) for their daily improvement of English language knowledge. Roughly a fifth of them (21.8\%) dedicate some time to English only a few times a week, while a third (31.6\%) never use electronic devices for such studies.

From these data, we can draw the conclusion that more than half of the respondents in all groups feel the need to engage with improvement of English regularly, but the PC seems to be the device of choice with academic and administrative staff, whereas students slightly prefer to use their smartphone. Among the most frequently used language learning apps for English were listed Duolingo, Beelinguapp, Busuu and Memrise.

Further information surfaced from responses to the question "What kind of language information do you normally search for on the smartphone or tablet?" Namely, a number of language enhancing facilities seem to be regularly exploited, but were not considered among the language learning tools by the respondents. Thus, an overall $72.6 \%$ of respondents (students: $75.2 \%$; teachers: $69.2 \%$, administration: 63.3\%) declared that they regularly used their smartphones to check up the meaning of English words. Translation tools, such as Google Translate or Speak\&Translate, qualified as another frequently used mobile app by the respondents (72.6\% overall; students: $75.6 \%$; teachers: $66.7 \%$, administration: $66.1 \%)$. The respondents refer less frequently to the mobile apps in order to verify grammar (overall mean $43.9 \%$ ) or pronunciation (overall mean $36.6 \%$ ) or sample language exercises (overall mean $13.7 \%$ ). Only $8.5 \%$ of respondents stated that they never used their smartphones to search for language information (Table 2).

Table 2. Searching for language information on smartphones or tables

\begin{tabular}{|l|r|r|r|r|r|r|r|c|}
\hline & \multicolumn{9}{|c|}{ What do you participate as? } \\
\hline & \multicolumn{2}{|c|}{ Student } & \multicolumn{2}{|c|}{ Administrative staff } & \multicolumn{2}{c|}{ Teacher } & \multicolumn{2}{c|}{ Total } \\
\hline & $\mathrm{n}$ & \multicolumn{1}{|c|}{$\%$} & $\mathrm{n}$ & $\%$ & $\mathrm{n}$ & $\%$ & $\mathrm{n}$ & $\%$ \\
\hline Vocabulary meaning & 515 & $75.2 \%$ & 69 & $63.3 \%$ & 162 & $69.2 \%$ & 746 & $\mathbf{7 2 . 6 \%}$ \\
\hline Grammar & 325 & $47.4 \%$ & 44 & $40.4 \%$ & 82 & $35.0 \%$ & 451 & $\mathbf{4 3 . 9 \%}$ \\
\hline
\end{tabular}




\begin{tabular}{|c|c|c|c|c|c|c|c|c|}
\hline & \multicolumn{8}{|c|}{ What do you participate as? } \\
\hline & \multicolumn{2}{|c|}{ Student } & \multicolumn{2}{|c|}{ Administrative staff } & \multicolumn{2}{|c|}{ Teacher } & \multicolumn{2}{|c|}{ Total } \\
\hline & $\mathrm{n}$ & $\%$ & $\mathrm{n}$ & $\%$ & $\mathrm{n}$ & $\%$ & $\mathrm{n}$ & $\%$ \\
\hline Translation & 518 & $75.6 \%$ & 72 & $66.1 \%$ & 156 & $66.7 \%$ & 746 & $72.6 \%$ \\
\hline Pronunciation & 281 & $41.0 \%$ & 20 & $18.3 \%$ & 65 & $27.8 \%$ & 366 & $35.6 \%$ \\
\hline $\begin{array}{l}\text { Exercises for language } \\
\text { improvement }\end{array}$ & 104 & $15.2 \%$ & 19 & $17.4 \%$ & 18 & $7.7 \%$ & 141 & $13.7 \%$ \\
\hline Other & 3 & $0.4 \%$ & 1 & $.9 \%$ & 3 & $1.3 \%$ & 7 & $0.7 \%$ \\
\hline $\begin{array}{l}\text { I don't use my } \\
\text { smartphone/tablet to } \\
\text { search for language } \\
\text { information }\end{array}$ & 33 & $4.8 \%$ & 17 & $15.6 \%$ & 37 & $15.8 \%$ & 87 & $8.5 \%$ \\
\hline
\end{tabular}

On a five-point Likert scale it was verified to what extent respondents agreed or disagreed with various statements regarding the usefulness and convenience of using electronic devices to learn or improve their language skills (Table 3). All three categories of participants mostly agreed with the statement "I'm comfortable using technology and mobile devices for language learning" (students - mean value: 4.4; administrative staff - mean value: 4.2 ; teachers - mean value: 4.2 ). The two other important statements for students were: "Teachers should encourage students to use mobile apps for language learning" (mean value: 4.0) and "Using a mobile app to learn English improves my language skills" (mean value: 3.9 ). The statement with a lower mean value for all 3 categories was: "I think that my time spent learning languages on an electronic device is more effective than conventional courses" (students - mean value: 3.0; administrative staff - mean value: 2.9 ; teachers - mean value: 2.9$)$.

Table 3. Statements about the usefulness and convenience of using electronic devices for language learning

\begin{tabular}{|l|r|r|r|r|r|r|}
\hline & \multicolumn{3}{|l|}{ What do you participate as? } \\
\hline & \multicolumn{2}{|l|}{ Student (n=685) } & \multicolumn{2}{|c|}{$\begin{array}{c}\text { Administrative } \\
\text { staff (n=109) }\end{array}$} & \multicolumn{2}{|c|}{$\begin{array}{l}\text { Teacher } \\
\text { (n=234) }\end{array}$} \\
\hline & $\begin{array}{l}\text { Mean } \\
\text { value }\end{array}$ & SD & $\begin{array}{l}\text { Mean } \\
\text { value }\end{array}$ & SD & $\begin{array}{l}\text { Mean } \\
\text { value }\end{array}$ & SD \\
\hline $\begin{array}{l}\text { Using a mobile app to learn English } \\
\text { improves my language skills. }\end{array}$ & 3.9 & 1.0 & 3.9 & 1.0 & 3.6 & 1.1 \\
\hline $\begin{array}{l}\text { I think that my time spent learning } \\
\text { languages on an electronic device is } \\
\text { more effective than conventional } \\
\text { courses. }\end{array}$ & 3.0 & 1.2 & 2.9 & 1.2 & 2.9 & 1.1 \\
\hline
\end{tabular}




\begin{tabular}{|c|c|c|c|c|c|c|}
\hline & \multicolumn{6}{|c|}{ What do you participate as? } \\
\hline & \multicolumn{2}{|c|}{ Student $(n=685)$} & \multicolumn{2}{|c|}{$\begin{array}{l}\text { Administrative } \\
\text { staff }(n=109)\end{array}$} & \multicolumn{2}{|c|}{$\begin{array}{l}\text { Teacher } \\
(\mathrm{n}=234)\end{array}$} \\
\hline & $\begin{array}{l}\text { Mean } \\
\text { value }\end{array}$ & SD & $\begin{array}{l}\text { Mean } \\
\text { value }\end{array}$ & SD & $\begin{array}{l}\text { Mean } \\
\text { value }\end{array}$ & SD \\
\hline $\begin{array}{l}\text { Getting online information about } \\
\text { language is better than looking } \\
\text { through books. }\end{array}$ & 3.6 & 1.1 & 3.5 & 1.2 & 3.6 & 1.2 \\
\hline $\begin{array}{l}\text { I'm comfortable using technology } \\
\text { and mobile devices for language } \\
\text { learning. }\end{array}$ & 4.4 & 0.9 & 4.2 & 0.9 & 4.2 & 0.9 \\
\hline $\begin{array}{l}1 \text { would like to use more online } \\
\text { resources and apps to learn English. }\end{array}$ & 3.8 & 1.2 & 4.0 & 1.1 & 3.7 & 1.1 \\
\hline $\begin{array}{l}\text { Teachers should encourage } \\
\text { students to use mobile apps for } \\
\text { language learning. }\end{array}$ & 4.0 & 1.0 & 3.9 & 1.1 & 4.0 & 0.9 \\
\hline
\end{tabular}

The participants were also asked if they considered the ease and accessibility of mobile learning a motivating factor for language learning. The most frequent replies were "Yes, probably" (48.3\%) and "Yes, definitely" (32.9\%). These results were further confirmed by the answers to the question "Do you plan to learn a new language using mobile app in the future?", to which $33.6 \%$ of respondents replied "Yes, probably" and 26.8\% "Yes, definitely". These respondents were asked a follow-up question: "Which language do you plan to study?". The vast majority of respondents (92.9\%) opted for one of the European languages (mainly Spanish, German, French and Italian - in order of hits), while $16.9 \%$ considered also learning an Asian language (Chinese, Japanese and Korean were listed). Only 2.3\% of respondents did not answer this question. There are no significant differences between categories of participants and by institution. It is interesting to note that all the languages of the LanGuide partnership (Spanish, Romanian, Swedish, Croatian, Slovenian, Italian) also figured in respondents' selection.

It can be deduced that the vast majority of our respondents regularly (or even daily) engage in some sort of expansion and refinement of English in their free time or at work/study using an electronic device. While only about a third consider such an activity as language learning and even fewer (13.7\%) use mobile apps to study in language courses or do language exercises in English, they strongly agree that mobile apps can enhance further development of their language skills. They, therefore, expect language teachers to encourage their further engagement with languages via mobile apps; especially in view of the fact that these resources are available everywhere and most respondents feel confident of their IT skills. Thus, 
also the enthusiasm indicated by their plans to learn new languages. In order to satisfy the ambitions of our students and cater to the new learning needs, new insights should be gathered from more experimental testing of new methodologies, as planned within the future activities of the LanGuide project.

\section{Conclusions and recommendations}

Mobile language learning has altered the approach to language acquisition and our respondents prove well aware of the options available to them. The mobility, portability, and ubiquity of mobile apps seem to motivate them to make plans for more language learning. The manner of language acquisition that provides a sense of freedom and self-management seems to suit and motivate self-learners, however, particular attention should be devoted to further investigation of learning strategies and learning styles compatible with the use of mobile technology. Such knowledge can have a crucial impact on both language instructors and learners of foreign languages, as well as help materials writers and software developers.

\section{Acknowledgement}

This research was supported by the Erasmus+ grant number 19-203-060377 - KA2$\mathrm{HE}-01 / 19$.

\section{References}

Bernacki, Matthew L., Jeffrey A. Greene, and Helen Crompton. 2020. “Mobile technology, learning, and achievement: Advances in understanding and measuring the role of mobile technology in education." Contemporary Educational Psychology 60: 1-8. https://doi.org/10.1016/j.cedpsych.2019. 101827.

Brick, Billy and Tiziana Cervi-Wilson. 2015. "Technological diversity: A case study into language learners' mobile technology use inside and outside the classroom." In 10 years of the LLAS elearning symposium: Case studies in good practice, ed. by Kate Borthwick, Erica Corradini, and Alison Dickens, 21-30. Dublin: Researchpublishing.net. https://doi:10.14705/rpnet.2015.000264 
Broadbent, Jaclyn. 2017. “Comparing Online and Blended Learner's Self-Regulated Learning Strategies and Academic Performance." Internet and Higher Education 33, 24-32. https://doi.org/10.1016/j.iheduc.2017.01.004.

Conole, Grainne and Panagiota Alevizou. 2010. A literature review of the use of Web 2.0 tools in higher education. Higher Education Academy. Retrieved from https://www.heacademy.ac.uk/sites/default/files/Conole Alevizou_ 2010.

Elbabour, Fatnma and Milena Head. 2020. "Mobile Learning and Student Engagement in Higher Education: A Review." In SIGHCI 2020 Proceedings, 1-5. https://aisel.aisnet.org/sighci2020/2

Ibacache, Kathia. 2019. "Use of Language-Learning Apps as a Tool for Foreign Language Acquisition by Academic Libraries Employees." Information Technology and Libraries 38(3): 22-33. https://doi.org/10.6017/ital.v38i3. 11077

Jie, Zhang, Yu Sunze, and Marlia Puteh. 2020. "Research on Teacher's Role of Mobile Pedagogy Guided by the Zone of Proximal Development." In Conference: ICEIT 2020: 9th International Conference on Educational and Information Technology, 219-222. doi.org/10.1145/3383923.3383965

Kukulska-Hulme, Agnes. 2012. "Language learning defined by time and place: A framework for next generation designs." In Left to My Own Devices: Learner Autonomy and Mobile Assisted Language Learning. Innovation and Leadership in English Language Teaching, ed. by Javier E. Díaz-Vera, (6), 1-13. Bingley, UK: Emerald Group Publishing Limited.

Kukulska-Hulme, Agnes, Lucy Norris, and Jim Donohue. 2015. "Mobile pedagogy for English language teaching: a guide for teachers." London: British Council.

Lightbown, Patsy, Nina Spada. 2006. How Languages are Learned. Oxford: OUP.

Mutiaraningrum, Ira and Arif Nugroh. 2021. "Mobile assisted language learning application in higher vocational education in Indonesia." Journal of English Education Society 6(1): 26-34. https://doi.org/10.21070/jees.v6i1.793

Sharples, Mike, Josie Taylor, and Giasemi N. Vavoula. 2005. "Towards a Theory of Mobile Learning." Proceedings of mLearning, 2-10.

Sharples, Mike (ed.). 2006. Big Issues in Mobile Learning. Nottingham: Learning Sciences Research Institute.

Viberg, Olga and Ake Gronlund. 2012. "Mobile Assisted Language Learning: A Literature Review." Conference Proceedings: 11th World Conference on Mobile and Contextual Learning, 1-8.

Walsh, Maureen. 2010. "Multimodal Literacy: What does it mean for classroom practice?." Australian Journal of Language and Literacy 33(3): 211-239. 